\title{
Early and Late Haemodynaemic Effects after Adding Fentanyl to Bupivacaine-Lignocaine Mixtures in Supraclavicular Brachial Plexus Block: A Randomized Control Trial
}

\author{
F ZAINAB
}

\begin{abstract}
Background Objectives: Haemodynamic changes are very crucial issues during regional anaesthesia. The purpose of the present study was to observe the immediate and late haemodynaemic effects after adding fentanyl to bupivacainelignocaine mixtures in supraclavicular brachial plexus block.

Methodology: This randomized clinical study was conducted in the Department of Anesthesiology in Chittagong Medical College Hospital (CMCH) from March 2011 to May 2012 for a period of one year. All patients with the age group of 18 to 65 years who were selected for upper limb surgery distal to the mid arm were the study population. The random allocation of the patient was done into Group $A$ patients (control group) who were received injection Bupivacaine (0.25\%) with injection lignocaine $A$ (1\%) with injection Normal saline (0.9\%). Group B patients (treatment group) were received injection bupivacaine $(0.25 \%)$ with injection Ligonocaine A (1\%) with injection fentanyl. With all aseptic precaution, supraclavicular brachial plexus block was done using paresthesia technique. Pulse and blood pressure were measured at baseline, intra-operatively and post-operatively.

Result: A total of 60 patients were enrolled in this study with 30 patients in each group named group $A$ and group $B$. The mean age of group $A$ and group $B$ were $32.43 \pm 12.25$ and $34.90 \pm 13.05$
\end{abstract}

Introduction

Brachial plexus block is gaining popularity day by day over general anaesthesia for upper extremity surgery ${ }^{1}$. Local anesthetics with the mixture of different drugs are intended to provide faster block onset than long-acting agents which extend the duration typically seen with intermediate-acting or short-acting agents. These intermediate-acting or short-acting agents provide clinically significant advantages ${ }^{2}$. Bupivacaine is

Address of Correspondence: Dr. Farhanaz Zainab, Assistant Professor, Dept. of Anaesthesiology, National Institutes of Neuro-sciences (NINS), Sher-e-Bangla Nagar, Dhaka. Mobile: 01717372024,01717372023, E-mail: frzzainab41@gmail.com Received: 20 February, 2020 Accepted: 28 October, 2021 respectively ( $p=0.453)$. The mean pulse rate of group $A$ (79.53 \pm 5.03$)$ and group $B(78.10 \pm 4.26)$ at baseline level increased at the time of injection (88.30 \pm 5.77 and $85.63 \pm 4.87$ respectively). At 8 hours interval mean pulse rate of group $A$ was $86.47 \pm 5.51$ compared to that of group $B(86.07 \pm 3.08)$. The mean systolic blood pressure of group $A(126.50 \pm 18.21)$ and group B (120.07 \pm 11.61$)$ at baseline level increased at 0 minute at the time of injection $(129.70 \pm 15.34$ and $123.17 \pm 10.57$ respectively). The mean diastolic blood pressure of group $A$ (71.73 \pm 11.20$)$ and group $B(72.73 \pm 11.45)$ at baseline level increased at 0 minute $(75.97 \pm 12.74$ and $75.80 \pm 12.85$ respectively). At 8 hrs interval mean diastolic pressure of group A was $71.73 \pm 11.20$ compared to that of group B $(71.73 \pm 11.20)$.

Conclusion: In conclusion there is no significant immediate or late haemodynaemic effects after adding fentanyl to bupivacaine-lignocaine mixtures in supraclavicular brachial plexus block.

Keywords: Immediate effects; late effects; haemodynaemic changes; fentanyl; bupivacaine-lignocaine mixtures; supraclavicular; brachial plexus block

(J Bangladesh Coll Phys Surg 2022; 40: 17-22) DOI: https://doi.org/10.3329/jbcps.v40i1.57052

frequently in brachial plexus blocks. However, onset of action and duration of anesthesia are the limiting factors. To minimize these drawbacks, many drugs including buprenorphine, morphine, fentanyl and dexamethasone have been co-administered with local anesthetic to achieve quicker onset, improve the analgesic intensity and prolong the duration of action ${ }^{3}$.

The administration of opioid improves regional anaesthesia without centrally mediated side effects, it would be useful in clinical practice ${ }^{4}$. However, number of trials have examined the peripheral analgesic effect of opioids in a large variety of surgical settings particularly arthroscopy and conduction nerve blocks ${ }^{5}$. The addition of opioids in brachial plexus block is 
reported to improve success rate and postoperative analgesia ${ }^{6}$. Fentanyl could act directly on the peripheral opioid receptor. Primary afferent tissues have been found to contain opioid binding sites. Because the presence of bidirectional axonal transport of opioid binding protein has been shown, fentanyl may penetrate the nerve membrane and act at the dorsal horn. This could also account for the prolonged analgesia. However, fentanyl is reported to have a local anaesthetic action ${ }^{7}$. Furthermore, fentanyl may potentiate local anaesthetic action via central opioid receptor-mediated analgesia by peripheral uptake of fentanyl to systemic circulation.

The synergistic interaction between local anaesthetics and opioids with epidural administration has been reported $^{8}$. It appears that local anaesthetics and opioids exert their action independently via different mechanisms. Local anaesthetics block propagation and generation of neural action potentials by a selective effect on sodium channels, whereas opioids act on the opioid receptors creating an increase in a potassium conductance ${ }^{9}$. Jarbo et al $^{10}$ showed that morphine depressed both sodium and potassium currents associated with the action potential in squid giant axons. Therefore, the combination of local anaesthetics and opioids may effectively inhibit multiple areas of neuronal excitability.

Few clinical studies are carried out using fentanyl as an adjuvant in supraclavicular brachial plexus block. Considering the fact, this present study was undertaken to compare the immediate and late haemodynaemic effects after adding fentanyl to bupivacaine-lignocaine mixtures in supraclavicular brachial plexus block.

\section{Methodology:}

Study Settings and Population: This prospective, randomized, comparative, single-blinded clinical study was conducted in the Department of Anesthesiology in Chittagong Medical College Hospital (CMCH) in collaboration with orthopedics, general surgery and plastic surgery department. The hospital had 1000 bedded tertiary care hospital for Chittagong city and the surrounding district was covering around 10 million population. The duration of the study was from March 2011 to February 2012 for a period of one year. All patients with the age group of 18 to 65 years who were selected for upper limb surgery distal to the mid arm like elbow, forearm and hand in the departments of orthopedics, general surgery and plastic surgery of $\mathrm{CMCH}$ were the study population fulfilling the inclusion and exclusion criteria. Patients belonging to ASA grade I and II according to American Society of Anaesthesiologist classification normal healthy patients and patients with mild systemic illness respectively undergoing elective operation for upper limb distal to mid arm were include dint his study. Patients with coagulopatly, History of allergy to local anaesthetics, History of hypertension, History of peripheral neuropathy, History of chronic obstructive pulmonary disease, Psychological disorder or Anatomical distortion and infection at the site of injection were excluded from this study. Protocol was ethically reviewed, approved and institutional clearance was obtained from appropriate authority of Chittagong Medical College Hospital, Chittagong.

Randomization and Blinding: For random allocation of the patient into groups there were 2 cards. One card marked 'A' and another marked ' $\mathrm{B}$ '. Doctors on duty in the pre-anaesthetic assessment shuffled the cards and patients who consent for participating in the study were asked to draw a card blindly. Patients who drew card ' $A$ ' were allocated into Group-A while the patients who drew card marked 'B' were assigned to Group-B.

Allocation: Group A patients (control group) were received injection Bupivacaine $(0.25 \%) 19 \mathrm{ml}$ with injection lignocaine A (1\%) $19 \mathrm{ml}$ with injection Normal saline $(0.9 \%) 2 \mathrm{ml}$ (total $40 \mathrm{ml}$ ). Group B patients (treatment group) were received injection bupivacaine $(0.25 \%) 19 \mathrm{ml}$ with injection Ligonocaine A (1\%) $19 \mathrm{ml}$ with injection fentanyl 100ug ( $2 \mathrm{ml}$ ) (total $40 \mathrm{ml}$ ). Pre-anaesthetic assessment and informed written consent was taken from each of the patients who had fulfilled the inclusion and exclusion criteria and pre-operative fasting was kept for 6 hours. In the operation theatre, baseline pulse, NIBP (noninvasive blood pressure) were recorded. Block was performed with having all the facilities of resuscitation equipments and lifesaving drugs. With all aseptic precaution, supraclavicular brachial plexus block was done using paresthesia technique. The time to achieve complete block was noted. Intravenous sedation injection diazepam $(10 \mathrm{mg})$ and injection Ketorolac (30 mg IM) as an analgesic were given according to patient's requirement. Any occurrence of side effect in the postoperative period was also noted.

Follow up and Outcome variables: Pulse and blood pressure were measured at baseline, intra-operatively 
and post-operatively. The time of block was noted and the patient was monitored with pulse oxymeter, NIBP (non-invasive blood pressure).

Statistical Analysis: All the relevant data were compiled on a master chart first. Statistical analysis of the results was obtained by using window based computer software devised with Statistical Packages for Social Sciences (SPSS-v18). The continuous data were expressed as mean $\pm \mathrm{SD}$. The categorical data were expressed as number and percentage and were analyzed with the Chi-Square test. An unpaired Student's t test was used to test for differences in means for continuous variables. A two-sided $\mathrm{P}<0.05$ level of significance was selected for all analysis.

\section{Result:}

This study was planned to compare the anaesthetic and analgesic efficacy of adding fentanyl to bupivacaine-lignocaine mixtures in supraclavicular brachial plexus block for upper limb surgery. A total of 60 patients were enrolled in this study with 30 patients in each group named group A and group B. Group A received lignocaine-bupivacaine mixtures ( $1 \%$ lignocaine-A, $0.25 \%$ bupivacaine) and was considered control group. Group B received fentanyl $(100 \mu \mathrm{g})$ with the local anaesthetic mixtures. The weight range of the study population was not significantly differ. The mean age of group A and group B were $32.43 \pm 12.25$ and $34.90 \pm 13.05$ respectively $(\mathrm{P}=0.453)$. No significant difference was found between the two groups with respect to age. (Table I).

Table-I

\begin{tabular}{lccc}
\multicolumn{4}{c}{ Mean Age among the Study Groups } \\
\begin{tabular}{lccc} 
Study Groups & Mean & Range & P value \\
\hline Group A & $32.43 \pm 12.25$ & 18 to 60 & $0.453^{*}$ \\
Group B & $34.90 \pm 13.05$ & 18 to 58 & \\
\hline
\end{tabular}
\end{tabular}

*NS = Non- Significant; $\mathrm{P}>0.05$ in unpaired Student's t test of significance

The mean pulse rate of group $\mathrm{A}(79.53 \pm 5.03)$ and group B (78.10 \pm 4.26 ) at baseline level increased at 0 minute (at the time of injection) $(88.30 \pm 5.77$ and $85.63 \pm 4.87$ respectively) which gradually decreased up to 4 hours after operation. At 6 hours interval mean pulse rate of group A was $84.03 \pm 4.87$ and that of group B was $82.67 \pm 3.93$. At 8 hours interval mean pulse rate of group A was $86.47 \pm 5.51$ compared to that of group B $(86.07 \pm 3.08)$. But there was no statistically significant difference between the groups with respect to changes in pulse rate measured at different time intervals (Table II, III).
Table-II

Comparison of Early Changes of Pulse at different times among the study groups

\begin{tabular}{llcl} 
Time & Groups & $\begin{array}{c}\text { Pulse } / \mathrm{min} \\
(\mathrm{Mean} \pm \mathrm{SD})\end{array}$ & P value \\
\hline Baseline & Group A & $79.53 \pm 5.06$ & $0.240^{\mathrm{NS}}$ \\
& Group B & $78.10 \pm 4.26$ & \\
0 minute & Group A & $88.30 \pm 5.77$ & $0.058^{\mathrm{NS}}$ \\
& Group B & $85.63 \pm 4.87$ & \\
5 Minutes & Group A & $85.13 \pm 3.23$ & $0.053^{\mathrm{NS}}$ \\
& Group B & $83.67 \pm 2.45$ & \\
15 Minutes & Group A & $81.34 \pm 3.43$ & $0.058^{\mathrm{NS}}$ \\
& Group B & $79.66 \pm 2.56$ & \\
\multirow{3}{*}{ 30 Minutes } & Group A & $77.80 \pm 4.59$ & $0.069^{\mathrm{NS}}$ \\
& Group B & $75.87 \pm 3.42$ & \\
60 Minutes & Group A & $74.10 \pm 3.91$ & $0.164^{\mathrm{NS}}$ \\
& Group B & $72.93 \pm 2.30$ & \\
\hline
\end{tabular}

*NS $=$ Non-Significant; $(P>0.05)$ in unpaired Student's t test of significance

Table-III

Comparison of Late Changes of Pulse at different times among the study groups

\begin{tabular}{llcl} 
Time & Groups & $\begin{array}{c}\text { Pulse/min } \\
(\mathrm{Mean} \pm \mathrm{SD})\end{array}$ & P value \\
\hline 2 Hours & Group A & $73.73 \pm 2.49$ & $0.135^{\mathrm{NS}}$ \\
& Group B & $72.67 \pm 2.94$ & \\
4 Hours & Group A & $73.80 \pm 2.28$ & $0.064^{\mathrm{NS}}$ \\
& Group B & $72.73 \pm 2.10$ & \\
6 Hours & Group A & $84.03 \pm 4.87$ & $0.237^{\mathrm{NS}}$ \\
& Group B & $82.67 \pm 3.93$ & \\
8 Hours & Group A & $86.47 \pm 5.51$ & $0.730^{\mathrm{NS}}$ \\
& Group B & $86.07 \pm 3.08$ & \\
10 Hours & Group A & $85.97 \pm 5.01$ & $0.159^{\mathrm{NS}}$ \\
& Group B & $84.37 \pm 3.56$ & \\
12 Hours & Group A & $84.20 \pm 3.97$ & $0.737^{\mathrm{NS}}$ \\
& Group B & $83.87 \pm 3.68$ & \\
\hline
\end{tabular}

The mean systolic blood pressure of group $\mathrm{A}(126.50 \pm 18.21)$ and group $\mathrm{B}(120.07 \pm 11.61)$ at baseline level increased at 0 minute at the time of injection $(129.70 \pm 15.34$ and $123.17 \pm 10.57$ respectively) which gradually decreased up to $2 \mathrm{hrs}$ after operation. At $6 \mathrm{hr}$ interval mean systolic blood pressure of group A was $128.13 \pm 9.58$ and that of group B was $123.70 \pm 10.14$. At 8 hrs interval mean systolic pressure of group A was $124.43 \pm 14.18$ compared to that of 
group B (124.40 \pm 9.96$)$. At $10 \mathrm{hrs}$ interval mean systolic blood pressure of group A was $126.27 \pm 18.08$ and that of group B was $120.07 \pm 11.61$. But there was no statistically significant difference between the groups with respect to changes in systolic blood pressure measured at different time intervals (Table IV, V).

\section{Table-IV}

\begin{tabular}{|c|c|c|c|}
\hline le & Groups & $\begin{array}{c}\text { Systolic BP } \\
(\text { Mean } \pm \text { SD) }\end{array}$ & $P$ value \\
\hline \multirow[t]{2}{*}{ 3aseline } & Group A & $126.50 \pm 18.21$ & $0.108^{\mathrm{NS}}$ \\
\hline & Group B & $120.07 \pm 11.61$ & \\
\hline \multirow[t]{2}{*}{ minute } & Group A & $129.70 \pm 15.34$ & $0.060^{\mathrm{NS}}$ \\
\hline & Group B & $123.17 \pm 10.57$ & \\
\hline \multirow[t]{2}{*}{ Minutes } & Group A & $126.40 \pm 13.37$ & $0.083^{\mathrm{NS}}$ \\
\hline & Group B & $121.03 \pm 9.93$ & \\
\hline \multirow[t]{2}{*}{5 Minutes } & Group A & $125.40 \pm 14.05$ & $0.073^{\mathrm{NS}}$ \\
\hline & Group B & $120.04 \pm 10.08$ & \\
\hline \multirow[t]{2}{*}{0 Minutes } & Group A & $124.47 \pm 14.02$ & $0.687^{\mathrm{NS}}$ \\
\hline & Group B & $123.17 \pm 10.57$ & \\
\hline \multirow[t]{2}{*}{0 Minutes } & Group A & $122.13 \pm 13.31$ & $0.145^{\mathrm{NS}}$ \\
\hline & Group B & $117.70 \pm 9.66$ & \\
\hline
\end{tabular}

Table-V

\begin{tabular}{lccc}
\multicolumn{4}{c}{$\begin{array}{c}\text { Comparison of Late Changes of systolic blood } \\
\text { pressure at different times }\end{array}$} \\
Time & Groups & $\begin{array}{c}\text { Systolic BP } \\
\text { (Mean } \pm \text { SD) }\end{array}$ & P value \\
\hline 2 Hours & Group A & $123.03 \pm 10.90$ & $0.962^{\mathrm{NS}}$ \\
& Group B & $123.17 \pm 10.57$ & \\
4 Hours & Group A & $127.10 \pm 9.55$ & $0.136^{\mathrm{NS}}$ \\
& Group B & $123.17 \pm 10.57$ & \\
6 Hours & Group A & $128.13 \pm 9.58$ & $0.087^{\mathrm{NS}}$ \\
& Group B & $123.70 \pm 10.14$ & \\
8 Hours & Group A & $124.43 \pm 14.18$ & $0.992^{\mathrm{NS}}$ \\
& Group B & $124.40 \pm 9.96$ & \\
10 Hours & Group A & $126.27 \pm 18.08$ & $0.119^{\mathrm{NS}}$ \\
& Group B & $120.07 \pm 11.61$ & \\
12 Hours & Group A & $124.43 \pm 14.18$ & $0.992^{\mathrm{NS}}$ \\
& Group B & $124.40 \pm 9.96$ & \\
\hline
\end{tabular}

*NS $=$ Not Significant $(\mathrm{P}>0.05)$; Student's $\mathrm{t}$ test of significance The mean diastolic blood pressure of group $\mathrm{A}$ $(71.73 \pm 11.20)$ and group $B(72.73 \pm 11.45)$ at baseline level increased at 0 minute (at the time of injection) $(75.97 \pm 12.74$ and $75.80 \pm 12.85$ respectively) which gradually decreased up to 2 hrs after operation. Then it began to rise and at $6 \mathrm{hrs}$ interval mean diastolic blood pressure of group A was $80.97 \pm 10.61$ and that of group B was $80.97 \pm 10.61$. At 8 hrs interval mean diastolic pressure of group A was $71.73 \pm 11.20$ compared to that of group B (71.73 \pm 11.20$)$. But there was no statistically significant difference between the groups with respect to changes in diastolic blood pressure measured at different time intervals (Table VI, VII).

Table-VI

\section{Comparison of Early Diastolic Blood Pressure at Different Times}

\begin{tabular}{llcl} 
Time & Groups & $\begin{array}{c}\text { Diastolic BP } \\
(\text { Mean } \pm \text { SD })\end{array}$ & P value \\
\hline Baseline & Group A & $71.73 \pm 11.20$ & $0.734^{\mathrm{NS}}$ \\
& Group B & $72.73 \pm 11.45$ & \\
0 minute & Group A & $75.97 \pm 12.74$ & $0.960^{\mathrm{NS}}$ \\
& Group B & $75.80 \pm 12.85$ & \\
5 Minutes & Group A & $75.97 \pm 12.74$ & $0.960^{\mathrm{NS}}$ \\
& Group B & $75.80 \pm 12.85$ & \\
15 Minutes & Group A & $74.95 \pm 12.60$ & $0.876^{\mathrm{NS}}$ \\
& Group B & $73.88 \pm 12.05$ & \\
30 Minutes & Group A & $71.73 \pm 11.20$ & $1.000^{\mathrm{NS}}$ \\
& Group B & $71.73 \pm 11.20$ & \\
60 Minutes & Group A & $75.97 \pm 12.74$ & $1.000^{\mathrm{NS}}$ \\
& Group B & $75.97 \pm 12.74$ &
\end{tabular}

*NS $=$ Not Significant $(\mathrm{P}>0.05)$; Student's t test of significance

Table-VII

Comparison of Late Diastolic Blood Pressure at Different Times

\begin{tabular}{llcc} 
Time & Groups & $\begin{array}{c}\text { Systolic BP } \\
(\text { Mean } \pm \text { SD })\end{array}$ & P value \\
\hline 2 Hours & Group A & $71.73 \pm 11.20$ & $1.000^{\mathrm{NS}}$ \\
& Group B & $71.73 \pm 11.20$ & \\
4 Hours & Group A & $75.97 \pm 12.74$ & $1.000^{\mathrm{NS}}$ \\
& Group B & $75.97 \pm 12.74$ & \\
6 Hours & Group A & $80.97 \pm 10.61$ & $1.000^{\mathrm{NS}}$ \\
& Group B & $80.97 \pm 10.61$ & \\
8 Hours & Group A & $71.73 \pm 11.20$ & $1.000^{\mathrm{NS}}$ \\
& Group B & $71.73 \pm 11.20$ & \\
10 Hours & Group A & $71.73 \pm 11.20$ & $1.000^{\mathrm{NS}}$ \\
& Group B & $71.73 \pm 11.20$ & \\
12 Hours & Group A & $71.73 \pm 11.20$ & $1.000^{\mathrm{NS}}$ \\
& Group B & $71.73 \pm 11.20$ & \\
\hline
\end{tabular}

*NS $=$ Not Significant $(\mathrm{P}>0.05)$; Student's t test of significance 


\section{Discussion:}

Brachial plexus block offers many advantages over general anesthesia for upper limb surgeries such as sympathetic block, better post-operative analgesia and fewer side effects ${ }^{9}$.Various approaches can be used to block brachial plexus providing anaesthesia and analgesia for upper extremity surgery ${ }^{11}$. In supraclavicular approach the plexus is blocked where it is most compactly arranged at the level of the nerve trunks. As a result, a block with rapid onset can be achieved. This approach also offers a high success rate for elbow, forearm, hand surgery because all the branches of the brachial plexus can be reliably blocked ${ }^{12}$. The popularity of this approach was limited in the past because of the risk of pneumothorax. The reported incidence of pneumothorax after supraclavicular block is $0.5 \%$ to $6.1 \% 6,7,9$. The incidence of pneumothorax is likely reduced by operator experience and using shorter needles with caution ${ }^{5,9,10}$. Local anaesthetics are used for this purpose. Bupivacaine is the most commonly administered drug in this purpose. However, it is cardiotoxic and its delayed onset of action is the limiting factors.

In this study, fentanyl has been used as an adjuvant along with bupivacaine and lignocaine-A local anaesthestic mixtures. A total of 60 patients were enrolled in the study after fulfilling inclusion and exclusion criteria. They were divided into two groups by card sampling method with 30 patients in each group. Patients of group A received $0.25 \%$ bupivacaine and $1 \%$ lignocaine-A and was considered control group. Patients of group B received fentanyl (100ig) along with bupivacaine and lignocaine-A mixtures.

The mean age of group A and group B were $32.43 \pm 12.25$ and $34.90 \pm 13.05$ respectively ( $\mathrm{P}=0.453)$. No significant difference was found between the groups with respect to age. Currently bupivacaine along with opioids are used intrathecally for cesarean section ${ }^{13}$. Neuraxial administration of opioids along with local anaesthetic improves the quality of intraoperative analgesia and also provide postoperative pain relief for longer duration. It has been postulated that the total duration of effective analgesia was significantly prolonged $(259.4 \pm 32.53 \mathrm{~min})$ in Group receiving bupivacaine and fentanyl. In a study by Shashikala et al ${ }^{14}$ and Aboel-Enin et a ${ }^{15}$ conclude that addition of fentanyl to local anaesthetic mixtures fastens the onset and prolong the duration of akinesia
$(294 \pm 17.89 \mathrm{~min})$ and improve quality of postoperative pain $(3.25 \pm 0.67 \mathrm{hr})$ in peribulbar block $(\mathrm{p}=0.00)$.

This study documents that the mean pulse rate of group A (79.53 \pm 5.03$)$ and group B (78.10 \pm 4.26$)$ at baseline level increased at the time of injection $(88.30 \pm 5.77$ and $85.63 \pm 4.87$ respectively) which gradually decreased up to 4 hours after operation. At 6 hour interval mean pulse rate of group A was $84.03 \pm 4.87$ and that of group B was $82.67 \pm 3.93$. It seems that the patients of group A required $1^{\text {st }}$ analgesic dose around 6 hours after operation (373.33 \pm 12.68$)$. It seems that sensation of pain may have increased the pulse rate. But there was no statistically significant difference between the groups with respect to changes in pulse rate measured at different time intervals.

From the result of the present study, it seems that that the mean systolic blood pressure of group A (126.50 \pm 18.21$)$ and group B (120.07 \pm 11.61$)$ at baseline level increased at the time of injection $(129.70 \pm 15.34$ and $123.17 \pm 10.57$ respectively) which gradually decreased up to 2 hours after operation. But there was no statistically significant difference between the groups with respect to changes in systolic blood pressure measured at different time intervals. Similarly, no statistically significant difference between the groups with respect to changes in diastolic blood pressure measured at different time intervals was found in this study. This notion is consistent with reports of previous studies ${ }^{13,15}$ which have shown that adding of fentanyl with the local anaestheatics results in improved anaesthetic and analgesic outcome without any side effects/ complications.

In this study no nausea, vomiting, pruritus, hematoma formation or respiratory distress have been reported. In addition no severe adverse events are also found. Marashi et a $1{ }^{16}$ have performed a similar study and have reported that there is no significant adverse events or severe adverse events are found which is consistent with the present study. This indicates that the drugs are not harmful to the patients.

\section{Conclusion:}

In conclusion this prospective, randomized comparative study of supraclavicular brachial plexus block with local anaesthetic mixtures, with or without fentanyl revealed that addition of fentanyl does not cause significantly pulse and early or late changes of systolic and diastolic 
blood pressure. No significant difference is found between the groups with respect to age. Therefore, no significant difference has been observed regarding changes in pulse, systolic blood pressure and diastolic blood pressure.

\section{References:}

1. Wedel DJ, Harlocker TT. Nerve blocks. In: Miller RD, Fleisher LA, John RA, Savarese JJ, Wiener-Kronish JP, Young WL, eds. Miller's Anaesthesia. USA: Elsevier Churchill-Livingstone; 2005: 1685-1718

2. Mcconachie I, Mcgeachie J, Barrie J. Regional anesthetic techniques. In: Healy EJT, Knight PR, eds. Wylie \& Churchill-Davidson's A Practice of Anaesthesia. London: Arnold; 2003: 599-628

3. Greengrass RA. Peripheral nerve blocks. In: Morgan GE, Michail MS, Murray MS, eds. Clinical anesthesiology. USA: Appleton \& Lange; 2006: 324-358

4. Neal MJ, Hebl JR, Gerancher JC, Hogan QH. Brachial Plexus Anesthesia: Essentials of Our Current Understanding. Reg Anesth and Pain Med 2002; 27:402-428

5. Brown DL, Cahill DR, Bridenbaugh LD. Supraclavicular nerve block: Anatomic analysis of a method to prevent pneumothorax. Anesth Analg 1993; 76: 530-34

6. Riegler FX. Brachial plexus block with the nerve stimulator: motor response characteristics at three sites. Reg Anesth 1992; 17: 295-299

7. Chakrabarty S, Chakrabarti J, Mandal MC, Hazra A, Das S. Effect of clonidine as adjuvant in bupivacaine-induced supraclavicular brachial plexus block: A randomized clinical study. Indian J Pharmacol 2010; 42: 73-76

8. Reuben SS, Reuben JP. Brachial plexus anesthesia with verapamil and/or Morphine. Anesth Analg 2000; 91: 279-83
9. Kim MS, Hwang BS, Hwang BM, Kang SS, Son HJ, Cheong YII et al. Effect of the Addition of Fentanyl and Midazolam to Lidocaine in a Supraclavicular Brachial Plexus Block. Korean J Anesthesiol 2008; 54(2): Pp 167-172

10. Jarbo K, Yatindra KB, Nidhi BP. Brachial Plexus Block with midazolam and bupivacaine improves analgesia.Can $\mathrm{J}$ Anesth 2005; 52: 822-6

11. Kapral S, Gollman G, Waltl B, et al. Tramadol added to mepivacaine prolongs the duration of an axillary brachial plexus blockade. Anesth Analg 1999; 88: 853-6.

12. Shrestha BR, Maharajan SK, Tabedar s. Supraclavicular Brachial Plexus Block with or without dexamethasone- a comparative study. Kathmandu University Med J 2003; 1: 158-60.

13. Nishikawa K, Kanaya N, Nakayama M, Igarashi M, Tsunoda K, Namiki A. Fentanyl improves analgesia but prolongs the onset of axillary brachial plexus block by peripheral mechanism. Anesth Analg 2000; 91: 384-387.

14. Shashikala TK, 2006. A comparative clinical study of subarachnoid block with $0.5 \%$ hyperbaric bupivacaine 10 $\mathrm{mg}$ and combination of $0.5 \%$ hyperbaric bupivacaine 10 mg with 12.5 ug of fentanyl in patients posted for caesarean section. Dissertation(MD). Rajiv Gandhi University of Health Sciences, Karnataka, Bangalore

15. Abo El Enin MAH, Amin IE, Abd El Aziz AS, Mahdy MM, Mostafa MM, Abo El Enin MAH. Effect of fentanyl addition to local anesthetic in peribulbar block. Indian $\mathrm{J}$ Anaesth 2009; 53: 57-63

16. Marashi SM, Sharifnia HR, Azimaraghi O, Aghajani Y, Barzin G, Movafegh A. Naloxone added to bupivacaine or bupivacaine-fentanyl prolongs motor and sensory block during supraclavicular brachial plexus blockade: a randomized clinical trial. Acta Anaesthesiologica Scandinavica. 2015 Aug;59(7):921-7. 